\title{
Ethnic Minority Women in Contemporary Chinese Comics: Design, Role and Identity
}

\author{
Xiyuan $\operatorname{Tan}{ }^{1 *}$
}

Published: April 11, 2020

\begin{abstract}
Ethnic diversity has become an important part of Chinese culture. Since the finishing of the ethnic minority classification project, artworks representing minority people have appeared in many different forms. Among the studies of ethnic minority representation, hardly has any discussed minority women in comics. This study will investigate the depiction of female ethnic minority characters in Chinese comics. I have chosen two comics that are representative for two different categories. The first work is Ling-Long, an original story that uses southern ethnic minority culture as context, which falls under the 'ethnic minority themed original stories' category. The second one is Gada Meilin, an adaptation of a famous Mongolian folktale, which falls under the 'adaptation of existing stories' category. The main female characters will be analysed from two aspects: the visual design and the role they play in the story. The former aspect will investigate their appearance, dress, facial expressions and body languages, while the latter will investigate their occupation, position and action in the story. After the analysis, I will discuss my thoughts from the perspective of an art practitioner and suggest some of my own possible ways of improving the character designs.
\end{abstract}

Keywords: ethnic minorities, Chinese comics, character design, female characters

\section{INTRODUCTION}

Ethnic minority culture is an essential part of Chinese society. With the completion of the government led ethnic classification project in the late 1970s, 55 ethnic minority groups were officially confirmed and classified. This cultural diversity has attached much importance by the government and is often promoted during art events. Students are expected to learn about minority groups in history and social science classes in school, resulting in almost every educated Chinese having a general understanding of Chinese ethnic minority culture. With government attention and popular interest in ethnic minorities, many fiction and non-fiction publications representing their cultures have been produced.

Previous research has revealed that images aiming to represent an ethnic minority group usually consist of more women than men, such as in Chinese history textbooks and in films that adapt ethnic minority folktales or use ethnic minority people as main characters (Harrell, 1995; Chu, 2018). This gender imbalance makes it worthwhile to look at the issue from a feminist perspective. The two studies mentioned above have involved discussions of female positions in the relevant contexts, but there are still many more forms of media that could be explored. I choose to investigate the medium of comics - firstly, as a Chinese female graphic art practitioner and a comic reader myself, I am familiar with the way sequential graphic narratives work and have background knowledge of the contemporary Chinese comic art market. Additionally, the comic book medium has been overlooked in earlier research of ethnic minority images (Chu, 2018; Gladney, 1995; Yang, 2011; Zhang, 1997), and my study is intended to contribute to this gap. Lastly, comic art on the representation of ethnic minority people is rare and worth investigating. In a context where ethnic minorities have been constantly misrepresented in multiple media such as films and tourism tableaux, it is useful to know how minorities are represented in comics.

Among the Chinese comics that involve ethnic minorities, some use this subject as the main feature of their works, while others use it to create diversity and/or exoticism. This paper will discuss ethnic minority female characters in ethnic minority themed comics and investigate how their gender identities, ethnic identities and roles are graphically depicted. My chosen study period, from 2010 onwards, acknowledges an important period when online and digital media in China developed rapidly and was hugely influential in popular culture (Wallis, 2011), 
leading to the rapid growth of the comic industry through the appearance of major comic websites and online mobile applications. ${ }^{1}$

\section{A DIFFERENT PERCEPTION OF 'ETHNIC MINORITY' IN THE CHINESE CONTEXT}

Ethnic grouping has been defined as 'a self-perceived inclusion of those who hold in common a set of traditions not shared by others with whom they are in contact' (De Vos, 1995:18), and 'a community whose heritage offers important characteristics in common between its members and which makes them distinct from other communities' (Modood et al., 1997:13). Both these definitions emphasise how the group members share common characteristics and use this to mark their distinctiveness from other groups. Studies on ethnic minorities in the western world often involve perceived racial differences, such as imagined to be between Blacks, Middle-East people and Asians (Central Office of Information, 1997; Modood et al., 1997; Romanucci-Ross and De Vos, 1995; Turton and Gonzalez, 1999). However, in China, people's views on ethnic minority rarely involve racial differences. Instead, Chinese people are inclined to recognise ethnic distinctions from cultural and linguistic differences (Poston and Yaukey, 1992). Not only the general public but also social scientists consider race as 'not a central factor' (Mackerras, 1987: 90) in terms of ethnic minority definition - they tend to view ethnic minorities as different 'nationalities', a 'historical category' defined by factors such as language, territory, economy and psychological make-up. I argue this is due to several reasons: firstly, most Chinese ethnic minorities have very similar visual racial features to the majority Han (such as yellow skin and black hair, although there are exceptions - for instance, Tibetans have a darker skin tone). Secondly, the Han majority group is so large that their racial features vary remarkably, so even if an individual has a distinctive ethnic appearance, Chinese people tend to think this is due to geographical influences rather than ethnic influences. Thirdly, intermarriages between the Han and the minorities have decreased unique ethnic features on both sides.

Generally, in China, the public does not see racial factors as important in defining ethnicity. There has been literature from biological anthropology, on factors such as facial structure or body size. For example, Liang defines Zhuang people as 'South-Asian Mongoloid', and that they have 'slightly darker skin compared to East-Asian Mongoloid', 'obvious cheekbones, thicker lips' and 'flat nose, thick and black hair' (2011:14, translated by the researcher). However, these nuanced racial differences are often ignored and seen as unimportant in visual culture. One explanation is that Chinese people, the potential audiences of these images, do not see racial features as an important factor that tells ethnic minorities apart, so that hence the creators of these images find it unnecessary to depict those racial features in comic art. As an illustrator myself, I argue that another reason is because these racial features are too subtle to depict.

Han dominance is one significant reason for the misrepresentations of ethnic minority groups. As the majority group in China (making up 94\% of the whole Chinese population), it has been seen as the centrepiece of the Chinese nation that both Han and ethnic minorities find it difficult to distinguish between 'Han-ness' and 'Chineseness' (Joniak-Lüthi, 2015). Han individuals see being Han as 'being ordinary' (Joniak-Lüthi, 2015: 20). It is understandable that the Han as a majority might have biased views on minorities or exaggerate the differences between themselves and the minorities to create a symbolic contrast. As for literature on the impact of Han dominance, one example is Dillon's (2016) introduction to Chinese ethnic minorities for western readers, which states some western misunderstandings of Chinese culture, specifically in the confusion of Han Chinese and general Chinese, and the impact of Han Chinese as a majority. He defines the Han Chinese as 'the majority population who speak one of the languages [...] that are grouped together as Chinese and whose written language and culture is expressed through the medium of Chinese characters' (2016: 2081).

Han Chinese is also viewed as the most 'advanced' or superior ethnic group, and is often used as the standard against which minorities are measured - another example of seeing the Han as normalised. This is also shown in Fan's article (Fan, 2016), in which he mentions that political belief and status are the crucial factors that determine whether a cultural group is advanced. In contemporary China's case, it is the Han-Chinese led Communist Party that marks the standards. Harrell (1995: 3) describes 'ethnic minority' as 'a variety of peoples of different origins, languages, ecological adaptations, and cultures'. Later in the article, the word 'peripheral' is used to describe ethnic minorities, and examples of how Han Chinese tried to 'civilise' them are given, as if they were primitive and uncivilised (1995: 3). This is also reflected in Chu's (2018) study, in which she finds that images of ethnic minority

\footnotetext{
${ }^{1}$ In this article, the Romanisation for the Chinese names is 'pinyin', an official Romanisation system for Standard Chinese used widely in mainland China. The names of the Chinese comic artists will be displayed in the conventional Chinese order, where surnames will be put in front of the given name. The names of the artworks mentioned will be displayed in their Romanised spelling followed by their original Chinese characters in brackets.
} 
people in popular textbooks tend to appear in rural, outdoor settings, wear traditional clothes and have less interaction with modern technology. Furthermore, the more exotic the minority group is, the more likely it is shown in textbooks, and therefore minorities with less distinctive attributes (Zhuang and Hui, for example) are shown less often.

\section{METHODOLOGY}

The methodology I have used in this article is primarily visual research, which I have used to analyse the images in terms of content, form, style and depiction (Pauwels, 2011). In this case, visual research is used to find out how the comic medium in China represents ethnic minority women through character designs, with emphasis on content and depiction.

There are a very limited number of Chinese comics that consist of ethnic minority characters. Therefore, instead of analysing a large number of characters from numerous works, I have picked out the female protagonists from two comics I have selected: Ling-Long and Gada Meilin, to conduct detailed, in-depth visual content analysis. These two works fall into two different categories of Chinese ethnic minority comics: the former is an ethnic minority themed original story, while the latter is a comic adaptation of an existing ethnic minority story. The nature of the two categories are very different, leading to different aims, target audiences and eventually, female character designs. I will first introduce the background of the creation of the work, its authors and genre. Then the visual contents will be analysed from two perspectives: 1) visual design, 2) role, identity and personality. The first perspective mainly involves the analysis of physical appearance, dress, facial expressions and body language. The second perspective looks at non-visual, behavioural aspects such as character occupation, status, action and interaction with other characters. It is possible that some aspects from the two perspectives are linked, for example, dress and character occupation. These links will be mentioned in the analysis.

Before I start discussing the two comics I have selected, I will review some literature on the representation of ethnic minorities in comics and other media in China. Most of the studies suggest that ethnic people have a high chance of being depicted as female, and their depictions vary significantly depending on the context. For example, when they are used for propaganda purposes, they tend to be more heroic and more likely to be involved in maledominated areas, but when they are used for culture communication purposes, they tend to play mild, submissive, serving roles, and their female sexuality is more explicit. These are two very different contexts, and the images are aimed at different audiences from different eras. Therefore, in the analysis of the comics I have chosen, I will also investigate whether the purpose of the story (e.g. communicating ethnic minority culture, or merely using ethnic culture to create exoticism) influences the depiction of the female characters.

\section{ETHNIC MINORITY CHARACTERS IN COMICS}

Multicultural representation in character design has been a widely discussed topic in the comic studies field in the west. Many have focused on the depiction of black people and the creation of black superheroes. For example, Brown (2001) has investigated black heroes created by Milestone comics, contextualised by their fandom. He notes that compared with white characters in American comics, their black counterparts often play the role of symbols rather than an individual person. This is further supported by Facciani et al. (2015), where they cite McDuffie's argument that characters from a non-dominant group (black, Asian, female etc.) 'can't be interesting because everything they do has to represent an entire block of people' (2015: 3-4). Racial stereotyping and underrepresentation have further been discussed by Singer (2002) and by Glascock and Pretson-Schreck (2004).

Compared to the discussion of minority characters in American superhero comics, little has been written about minority characters in Chinese comics, either in English or in Chinese, owing to the scarcity of ethnic minority people in Chinese comics compared with other forms of media such as film and propaganda posters. Several Chinese research papers have discussed ways of applying ethnic minority culture into comic books. For example, Tao (2017) discusses the efficiency of using the comic medium to promote Miao culture. Another example: Zhang's paper (2018) reviews the competence of using ACG (animation, comic and game) media to communicate ethnic minority culture in Guangxi, in which he argues that the comic is widely accepted by audiences of all ages and could use humour and caricature to convey ethnic culture in a more vivid way. Meanwhile, specific discussions on character art are seen less frequently. One example is the work completed by Yuan et al. (2012) that analyses character designs in picture books of Oroqen folktales, arguing that the designs tend to be symbolic but lack research into personality and facial features. Overall, current literature tends to discuss how artists could use ethnic minority cultures as inspirations for their works, but it lacks in-depth exploration and systematic analysis of previous comic works. 
In contrast to the scarcity and superficiality of the research on minority representation in Chinese comics, there is more comprehensive information on minority images in other media such as propaganda posters, film and tourism, which will be discussed in the following section. Some methods of representation used in these media forms can also be found in the two comics I discuss later in this article.

\section{IMAGES OF FEMALE ETHNIC MINORITY PEOPLE IN DIFFERENT MEDIA FORMS}

In analysing the representation of Chinese ethnic minorities in comics, the chosen areas to investigate are propaganda posters, film and tourism. This is due to two reasons: 1) these three media forms have been studied the most compared to other media forms and there is sufficient literature to review; 2) the representation of minority people in these three areas have all gone through artistic or creative processing instead of being documentarily represented (e.g., as in TV news and journalism articles). This corresponds to the comic medium which also involves the artistic process of summarising an ethnic minority group's culture into symbolic character designs.

\section{PROPAGANDA POSTERS}

A valuable investigation of ethnic minority people in Chinese propaganda posters has been made by Li (2000). He defines minority people as 'signifiers' of 'socialist prosperity', 'lack of progress and education', 'national security' and 'national unity' (2000: n.p.). Although he does not focus on images of women specifically, he has noted several situations where women, both Han and minority, have played important roles in the posters. In one poster, Share the Labor and Share the Fruit (artwork by Cai Zhenhua, 1957), women of different ethnic groups are shown dancing under a tree. Here, Li states that women 'appear as the source of [colour], gaiety, and exuberance' (ibid. 2000: n.p.) and symbolise the prosperity of socialism and a bright future. In part 2, $\mathrm{Li}$ discusses images showing minority people lacking education, such as Serf's Daughter Goes to University (artwork by Pan Shixun, 1973), The Spirit of Lei Feng is Passed on from Generation to Generation (artwork by Seleng Yexi, 1976) and Learn from Good Experience and Develop the New Mountain Areas (artwork by Shan Xihe, 1974).

The status of women in these posters are different - in the first and the second posters, women are depicted as central characters in the image and showing a high level of education (being able to go to university and tell stories to teenagers). However, in the third poster, a Han Chinese man is at the centre and is accompanied by ethnic minority women dressed in traditional clothes. In these examples, ethnic minority women can be seen playing two opposite roles: 1) educators educating others who are often minority people and 2) students being educated by others, especially Han. Awareness of educating women has been addressed in the posters, but the primary aim is to show that Chinese minorities lack education compared with Han. In part 3, Li (2000: n.p.) discusses a poster of a Kazakh woman shooting with a gun while galloping on horseback. Li argues that 'Her female body is set in sharp contrast with the gun in her hands, the black boots, and the ammunition bags around her upper body... Here, a female minority body, still [colourful] yet no longer in gaiety, on the horseback instead of on the dancing floor, is turned into a warrior icon that becomes a signifier for national pride and security'. This poster conveys the message that even ethnic women can contribute to protecting the country. In part 4, posters that convey the message of 'national unity' are discussed. In these posters, ethnic people are shown interacting with Han people and endorsing political leaders. Ethnic people, alongside Han peasants, workers and soldiers, have been used as 'defining features to mark "the people" (Li, 2000: n.p.). In these posters, most minority people are women dressed in traditional clothes. It seems that minority people are generally more likely to be female, especially when they are depicted together with the majority Han group, even though they are not deployed to convey gender-oriented messages.

\section{FILM}

Ethnic minorities scarcely appeared in Chinese films before 1949 as it appears that filmmakers believed that audiences would not expect them in this new, western medium (Clark, 1987). Nevertheless, the new creative producers of China decided to expand their audience and gradually, filmmakers began to include national minorities and produced several crucial works such as Serfs (a story about the struggle of Tibetan peasants, released in 1963), Third Sister Lin (a film adaptation of a Zhuang folktale, released in 1960) and Sacrificed Youth (a story about a Han schoolgirl's interaction with the Dai minority, released in 1985). Although these films are breakthroughs in that era, they have been criticised for being stereotypical, Han-centred (Zhang, 1997), and even for commodifying ethnic minorities by using their exoticism to attract film audiences (Gladney, 1995).

Wei (2018) has analysed ethnic minority films from a feminist perspective. She argues that female characters with strong personalities are often the centre of the story in such ethnic minority films (2018: 23-24). Also, the 
films display ethnic women as integral subjects to the main narrative (2018: 23). She also states that female character images in ethnic minority films are diverse - they can be a heroine, or a common housewife; a protagonist or a supporting character. But many of them have successfully entered domains that used to be male dominated such as the battlefield (2018: 24). However, their images could also appear on the other end of the conventional spectrum of roles for women, for example, in Sacrificed Youth, Dai minority women are 'evoked as the... eroticized Other' (Zhang, 1997: 81 ) and their sexuality is shown explicitly in the scene where they swim naked in the river. Yuan (2014) classifies the roles of female protagonists in ethnic minority films into three: 1) heroines in a revolutionary period; 2) model workers who devote themselves to constructing new China socialism; and 3) contributors to national unity. These three factors are very similar to the roles of minority people in propaganda posters discussed by Li (2000) - films at that time were used as means of propaganda, after all.

\section{TOURISM}

Ethnic tourism in China nowadays generally refers to 'tourism motivated by a... search for exotic cultural experiences, including visiting ethnic villages, minority homes and ethnic theme parks' (Yang, 2011: 562). Knowing that ethnic minorities play important roles in the diversity of Chinese culture, the Government uses their resources for attracting both tourists and further investment. As a result, the Government's involvement in ethnic tourism developments helps them improve the infrastructure, planning and destination potential of a place (Qin, Wall and Liu, 2011). Ethnic tourism sites can be found in many places in China, especially in the border areas such as Inner Mongolia, Xinjiang, Tibet and Yunnan.

Yang (2011) investigated the tourism industry in Yunnan Ethnic Folk Villages and discovered that 99\% of the tourist guides are young girls. He interviewed the manager who explained that they use women's colourful ethnic clothes to attract tourists. He also relates this to the commodification of ethnic minority culture and mentions that female characters are more closely connected to ethnic commodity production. This can be justified by the discussion by Yang et al. (2009) on the issue of using women dressed in colourful attire as performers of cultural stage shows, and requesting them to play the role of the bride in fictitious wedding ceremonies that involve male tourists pretending to marry minority women. Images of minorities in tourism present their cultures as feminised and exotic, and that women's 'beauty, purity and innocence' (Yang, Wall and Smith, 2008: 761) have become commodities that are central to standard tourism promotions.

Compared to the propaganda posters and film, images of minority women in tourism appear to carry fewer direct political messages - they are not warriors or heroines, instead they are mainly used as a means of conveying ethnic minority culture and as an entertainment. Female workers are more likely to be involved in activities that include interactions with tourists (e.g. tour guides, pretend 'brides'), whom are mostly Han, in which their exoticism is often accentuated.

\section{THE COMIC LING-LONG(灵珑) AND THE TAMING OF THE HEROINE}

Jin Yong's design of Lan Fenghuang, a character of Miao ethnicity (and a female character, as we would expect) in his work Xiao'ao Jianghu (笑傲江湖), has left a deep impression on Chinese readers, making them believe that southern ethnic minorities are often mysterious, eerie and fond of making poison (Tao, 2017). Male comic artist Wang Xiaoyang, the author of the comic Ling-Long (灵珑), has used this factor to create his own fantasy genre comic story. Ling-Long is a black and white comic that was published in 2010 and is an original story written by the author. Through my email interview with Wang, he told me that the inspiration for using ethnic minority culture in his comic came from a childhood experience, when he watched an ethnic minority-themed animation and was impressed by its mysteriousness. He also told me that he had read many books on ethnic minority cultures before he created the comic and has used this information for informing ethnic dress in his character designs.

Ling-Long is drawn in a conventional manga style - this is the case for many contemporary Chinese comics. Ethnic minority culture here is used as a context for the story. It is difficult to tell which specific minority he has referred to, but it can be inferred from the visual design of the characters and settings that it is a southern minority group (and this was later supported by my email interview with Wang). Ling-Long does hints slightly at the reader of the southern minorities. The communication of ethnic minority culture through the characters in Ling-Long can be considered as obvious as readers and fans have pointed out many references to southern minority clothes in the character designs. Ling-Long is not an adaptation of any southern minority folktale. However, the artist used southern ethnic minorities as a design reference for the characters and made their identity an enhancement of fantasy and mystery in the story, recalling the ideologies and stereotypes of minority people generated by their depictions in popular previous works such as Xiao'ao Jianghu. 
The first character I will analyse is Long, a 14-year-old girl, who is one of the two main protagonists in the comic. She appears in the story before the male protagonist, a 13-year-old boy Lingbao, and is the centre of the story.

\section{VISUAL DESIGN}

As shown in Figure 1, Long has a round face, round eyes, long black plaited hair and a tattoo-like symbol on her cheek that indicates her hidden magical powers. Her eyelashes and double eyelids are signifiers of her gender - both are conventional feminine visual cues that comic artists would be likely to use for their female character designs. Considering the general manga style of the comic, it seems that the artist has designed a universal face for her without acknowledging any racial influences on facial features (e.g. southern minorities are often believed to have obvious cheekbones and thicker lips).
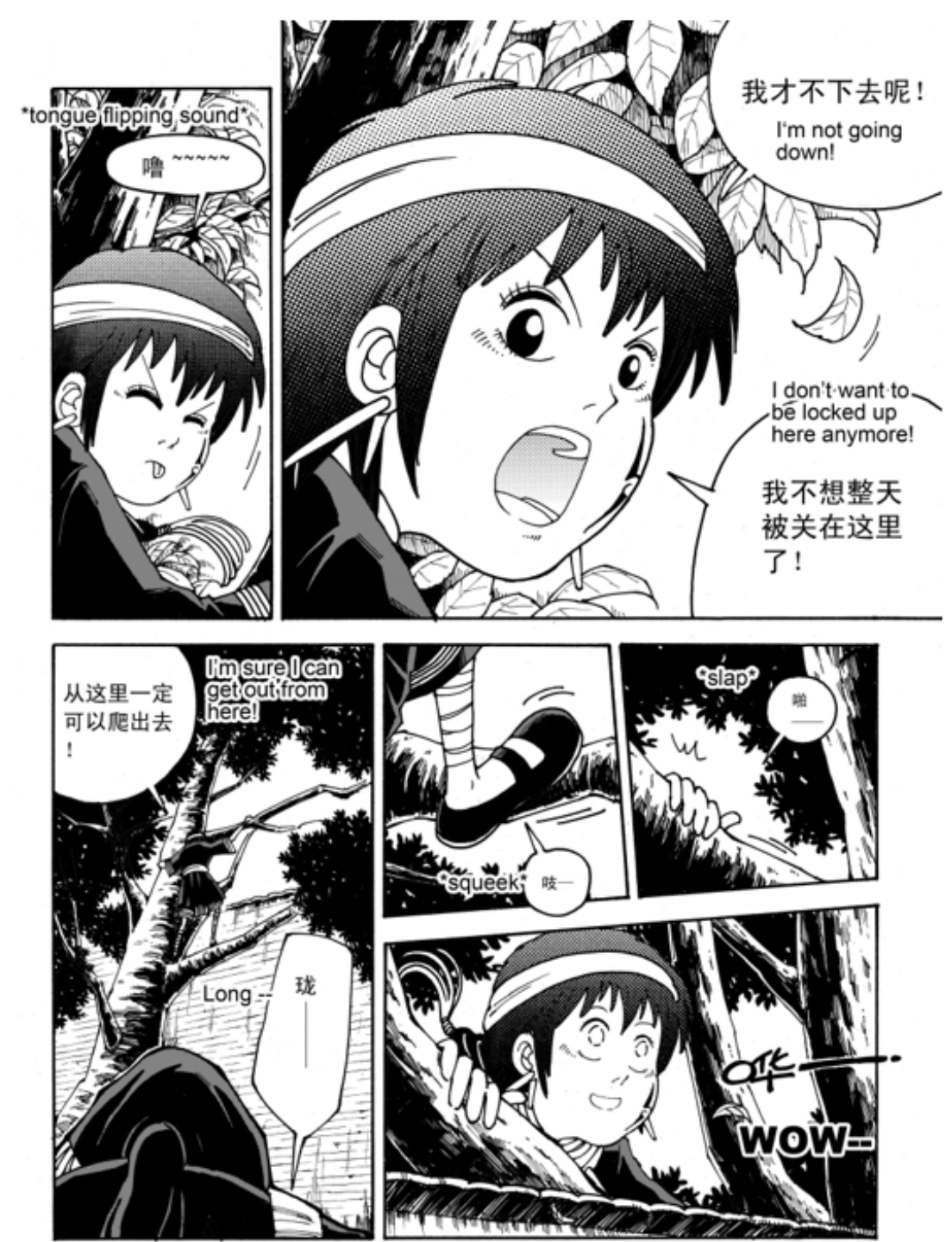

Figure 1. A page from Ling-Long. English translation of the text provided by me. Used with permission from the author

As argued earlier, ethnic minorities are rarely differentiated by race in China, whether within academia or nonacademia. Therefore, Wang uses dress to mark out her ethnic identity, as previous artists have done. Using dress to show a character's identity is often effective, either trying to express ethnicity or gender, as dress is considered 'a coded sensory system of non-verbal communication' (Eicher, 1995: 1). It is not only an indicator but also a producer of gender (Barnes and Eicher, 1992). The character Long wears symbolic southern minority clothes and jewellery- dark coloured short-sleeve top and skirt, silver neck rings and earrings. These visual elements explicitly convey the messages of her ethnicity and female gender, as well as adding character exoticism. They also indicate her high social status, since jewellery is a sign of wealth, and other female characters in the comic do not wear such 
jewellery. As for the face and body, she has rich and exaggerated facial expressions and body movements. For example, there are panels depicting her laughing wildly, shouting, kicking people and stretching her arms and fists up in the air, as shown in Figure 2. They reflect her extroverted, lively and energetic personality. This personality is further accentuated through the contrast with other characters. The panels in Figure 2 also depict another character, who is Long's mentor friend. His character images create a sharp contrast with Long's. While Long is stretching out her limbs and full of facial expressions, this character displays a rather still body and a cold face. Although some other characters are also depicted with exaggerated facial expressions (a common feature in the manga-style), they show much less body language exaggeration compared to Long.

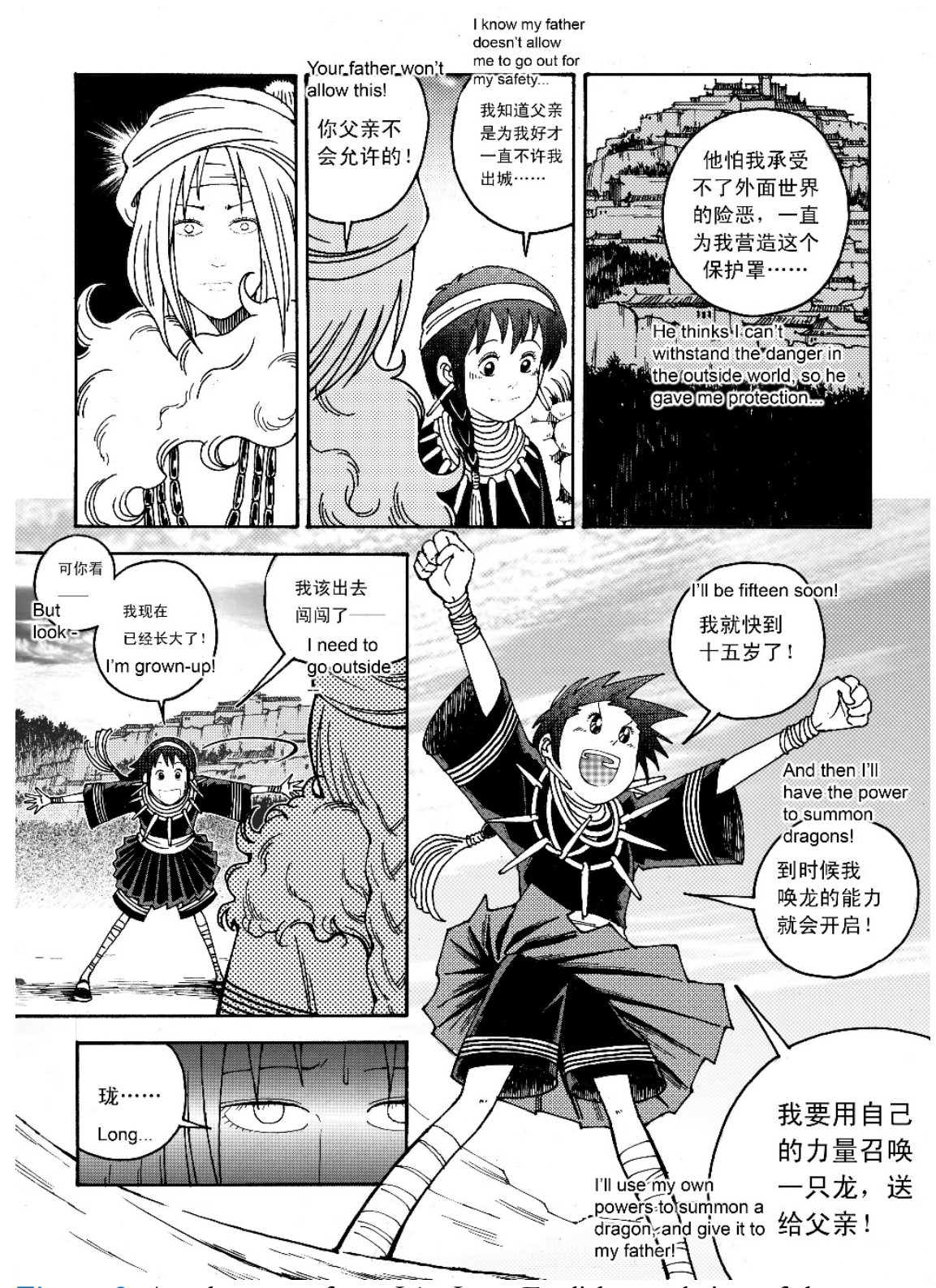

Figure 2. Another page from Ling-Long. English translation of the text provided by me. Used with permission from the author

Apart from Long's eyelashes, hair and skirt, there are a few other visual cues that show the construction of her femininity. Her loose clothing covers the feminine curves of her body. However, her aggressive facial expressions and body postures display traits that are generally considered masculine. But as the story goes on, Long goes through events and challenges that gradually decrease her naughtiness and childishness. Compared to the first half of the comic, there are fewer images of her with exaggerated facial expressions and body language. Later in the comic, her body language even starts to show her submission to male characters (e.g., leaning her head on their shoulders), which I will discuss in the following section. 
Long is the adopted daughter of the town lord and has the magical power to summon dragons when she reaches 15 years of age. She is of high social class or status, as displayed by her dress and jewellery, but is shown to be disliked by regular townspeople for her childishness and uselessness. She displays a naughty and rebellious personality and is sometimes immature and impolite. Some examples are shown at the beginning of the comic, such as her tongue-flicking at her guardian in Figure 1 and her later act of selling a priceless antique artefact for a block of gold. She also enjoys being dominant and controlling. In the story, she succeeds in disobeying her father's orders and goes on an adventure with Lingbao.

Considering that the target audience of this comic is teenagers, it is understandable that Wang has constructed a protagonist who is about the same age and has similar personalities as the readers such as rebelliousness and impulsivity so that they can easily identify with her (Ono, 2007) and perhaps the intention is that they then reflect upon themselves. What makes Long special is that she is an ethnic minority female character. I have asked Wang why he chose to use an ethnic minority girl as the protagonist, he answered, 'Just think about a rebellious ethnic minority young girl...it gives us the feeling that she is full of stories!'. From this answer, it could be inferred that Wang has considered both ethnicity and gender as factors that dramatise the story. Since Wang also mentioned the 'mysteriousness' that he sensed from ethnic minority culture, it is likely that he has related 'mysteriousness' to 'full of stories.'

However, Long's personality changes after she starts her journey with the male protagonist Lingbao - just like the changes in her visual appearance discussed earlier. When she sets off her journey with Lingbao, she keeps her commanding personality and has a domineering attitude towards him. As the story goes on, she gradually becomes more passive and submissive, and even reliant on Lingbao. Although Long is the characters with the magical powers, Lingbao is character that makes crucial decisions, guides and directs the journey. There is even a panel showing Long leaning on Lingbao's shoulders and sleeping - a scene, I would argue, that notably displays the female protagonist's submission and reliance on the male protagonist. This is amplified by the fact that Lingbao is younger than Long. In terms of ethnicity, Lingbao is also shown as having a southern ethnic minority identity through his accessories - the lock he wears, for example, is a typical talisman for children in the Miao ethnic group. Both being southern minority characters, Long and Lingbao's interactions do not indicate any majority group dominance. During the climax of the story, Long discovers that she was being used by family and friends for the entire time as a sacrifice to the resurrection of dragons. She becomes an 'object' to her stepfather and mentor friend, both of whom are male. The characters who act as warriors and heroes for the decisive battle at the end are also male - the male protagonist Lingbao and a male dragon. She is totally under the control of the male characters at the peak of the story, despite her rebellious attitude and independence shown at the beginning.

To summarise, Wang creates a female protagonist who displays the commonly seen masculine, disobedient personality in propaganda and film images of ethnic minority women at the beginning, but later turns out to be carrying the stereotypical passive roles of female characters when the story reaches crucial points. Rather than a sign that reflects her pride and defiance as a high-status protagonist, her rebellious personality demonstrates her immaturity. As the one of the few characters that carry inhuman power and a central character that is surrounded by her supporters, she seems useless in the story and ends up requiring help from others, most of whom are the male 'helper'. Furthermore, the artist created a teenage character for this teenage-aimed comic, and this could be seen as intended to influence the minds of teenage readers, since the readers could use the character designs to reflect upon themselves. Research has shown that compared to conventional books, teenagers are more attracted to graphic novels and comics (Crawford, 2004; Snowball, 2005, 2007). Chances are that Wang had this in mind and was using his story to convey perceptions of appropriately gendered behaviour to teenagers. This not only includes their views on comic character gender stereotypes, but also their ideas on how gender works in real life, and is suggesting that even if a girl is a tomboy, she will be 'tamed' into appropriate femininity by the end of the story.

\section{MUDAN: A BRAVE WOMAN WHOSE HEROIC PERSONALITY IS NOT SHOWN BY HER APPEARANCE}

One important part of Chinese ethnic minority cultures are the tales and stories. These stories have been useful resources for graphic art adaptations. There have been many works produced since the completion of the ethnic classification project, most of which were picture books for children that were used to educate them about folklore and ethnic diversity in China. Some examples are the Hansheng Chinese Fairy-tales series published by Hansheng press (1982), Ethnic Minority Folktales series published by Shanghai People's Fine Art Press (1984) and Classical Myths of China's 56 Ethnic Groups series published by New Buds Publishing House (2013). Comic versions appeared at a 
later stage and are very scarce. One of the works is the comic adaptation of the legendary story of the Mongolian national hero, Gada Meilin², which was published in 2013. The main artist is a male Mongolian cartoonist, Bao Bailong, who did the character designs for the main characters. He cooperated with Li Yueyun and other comic artists in the animation and comic studio of Inner Mongolia Xinhua Publishers to create and publish the comic.

Despite being a cartoonist, Bao did not use much visual cartoon language for the character designs. By cartoon language, I refer to features such as distortions in body shape, exaggerated body proportions, squash and stretch techniques, depiction of characters in dramatic contexts and comedic features (Bishko, 2007). As an adaptation of a famous ethnic minority tale, this comic uses Mongolian ethnic minority culture as the main feature and a selling point. Visual cues of Mongolian life and traditions can be noticed everywhere in the panels: vast grassland scenes, horses, Mongolian tents, traditional nomad clothes, and even small details like Mongolian food on plates. All of this show the artist's intention of accentuating and communicating the Mongolian-ness.

The character I will analyse in this comic is the wife of the male protagonist Gada Meilin, Mudan Qiqige (referred to as Mudan later). According to the original history of the tale, Mudan was born into a rich family and practised martial arts, horse archery and shooting from a young age. She also received a good education. She is viewed as a liberated woman, which was rare on the Khorchin grasslands. Some historians believe that Gada Meilin would not have been as successful without the support of Mudan, and that her actions explicitly display feminism, since she did not merely act to help her husband, but also regarded the revolution as her own cause (Henochowicz, 2011).

\section{VISUAL DESIGN}

Mudan is depicted as a young woman. She has an average sized, round face, tied-up long black hair and almondshaped eyes. Similar to the design of Long, the visuals of her face do not obviously speak of her ethnic identity with what is believed to be typical racialised features - minority people in the northern steppe areas of China are believed to have smaller slant eyes, single eyelids and larger faces, but Mudan's face is an average Chinese female face. As for dress, she wears a bright green headband and a top with bright green sleeves and black cuffs decorated with floral patterns. The black vest she wears is a traditional Mongolian vest. In her design, the vest is decorated with the same floral patterns as those on her cuffs, and has blue and pink near the edges of the garment. In terms of facial expressions and body language, Mudan does not have abundant and exaggerated expressions like Long. She is generally calm, gentle, serious and mature. In the panels, she often appears accompanying her husband.

Mudan's feminine gender is displayed by her face and clothing. Although there are no obvious graphic signifiers such as long eyelashes, her gender can be seen from the comparison of her face to those of male characters. As one of the very few women in the story, her face stands out from the male characters with a relatively fairer skin colour and smoother lines, highlighting her femininity. Her clothing is a more obvious sign of her gender as well as ethnicity - the bright colours and floral patterns on her clothes work together to exhibit the stereotypical idea of colourfulness and gaiety of ethnic women, just like the images in propaganda posters. Additionally, the bright colour and elaborate patterns are also symbols of her high status and role as a protagonist. They make her stand out from other female characters, as they do not have such colourful and patterned dress. The classic structures of the traditional Mongolian attire are also intended to represent her Mongolian-ness.

\section{ROLE, IDENTITY AND PERSONALITY}

As the wife of a respected leader, Mudan is also respected by other nomads and must take up responsibilities for the revolution and get involved in conflicts between the nomads and the authorities. She is a mother with one daughter and her role as a parent is reflected with her caring and mature personality. On the other hand, she has a heroic characterisation and has a strong will. She even abandons her femininity and motherhood in serious situations, for example, killing her own daughter (though it is proved later that this is only made up - her daughter died due to illness (Dejide, 2008)) and rushing into the frontlines with a pistol in the hand. Like the Kazakh woman in the propaganda poster discussed earlier, Mudan's actions show a sharp contrast with her colourful, female dress.

Compared to Long, Mudan seems to be exactly the opposite as a character. Long's visual design displays rebelliousness and independence, but her role in the story is still reliant and passive; Mudan's visual design displays gentleness and womanhood, but her role in the story demonstrates her decisiveness, toughness and bravery. Despite being one of the few women in the rebellion, she is not a follower of the dominant gender. Instead, she shows charisma and leadership of her own, leads the nomad rebels and makes crucial decisions for them while her

\footnotetext{
${ }^{2}$ Rather than the name, this is the title of the hero. It is sometimes written as 'Gada Meiren'. I will use this pinyin version
} throughout the article. 
husband is in danger. As an obvious challenge to the existing gender role conventions, she has rescued her husband several times during the rebellion. However, the objectification of women is demonstrated at the end of the story, in which Gada Meilin is killed by Han Shewang's men and Mudan is then forced to marry Han Shewang. Mudan's forced marriage not only shows a significant contrast to her role as a brave, revolutionary heroine, but also indicates that in her era, no matter how strong a woman is, she is not able to decide whom she will be married to.

The fact that the adapted tale, Gada Meilin, has a heroic and rebellious theme also contributes to the unconventional gender roles of Mudan. Since this work is an adaptation of an existing tale, Mudan's personalities, behaviours and actions are pre-determined by the folktale itself rather than by the comic artists. However, the comic artists have much freedom on the visual design and they chose to give her conventional feminine visual elements - fair skin, bright colours and floral patterns, in spite of the masculine roles she plays. I suggest that there are two possibilities: either the artists have not done enough research into Mudan's position in the historical tale, so they designed her as a visually clichéd female ethnic character or the artists did notice her atypical roles but wanted to create the sharp contrast between her appearance and personality. Should it be the former, it reflects the widespread dominance of the visual stereotypes of ethnic female characters on comic artists - or to be specific for this case, the dominance of Han-centred visual stereotypes on Mongolian artists.

\section{CONCLUSIONS AND NOTES AS A PRACTITIONER}

The comparison of the two selected works reveals that female ethnic minority characters in Chinese comics shows two different possible narratives of femininity. The design strategies and character encoding resemble those of other visual forms, such as film and propaganda posters. Visually speaking, both examples emphasise the characters' garments and clothing Although the levels of details vary, the dress of the character is considered a symbol of their ethnic identity. Using typical attire is a straightforward way of visually depicting a person from a different cultural background in the Chinese ethnic minority cultural diversity context, where there is little difference in skin colour or facial features. Besides, clothing is an important aspect of a character, and is a more iconic way to emphasise distinctive features compared to working on the nuances of facial features. Dress also conveys non-verbal gender and social class/status messages, as shown with jewellery and floral patterns. Facial designs and body language communicate gender messages in Chinese comics but not, generally speaking, ethnicity messages. Visual conventions of gender can be found in both Long and Mudan such as long eyelashes, fair skin and smooth lines for face contours. Ethnicity-oriented racialised facial differences are not shown explicitly in either the characters. Since clothing design could already convey enough information, the artists chose to apply universal approaches to the depiction of the face. Body language gives gender information by the characters' interactions with other characters, especially male characters. Long's leaning on the male protagonist's shoulder and Mudan's serving food for the nomads are two obvious examples of the artists' intentions of showing typical roles in conventional femininity.

In terms of characterisation, both examples show rebellion and submission, but the orders they appear in the stories are different. Long displays naughtiness and rebellion at the beginning but gradually reduces her rebelliousness and starts following the guidance of male characters as the story unfolds toward conventional feminine subservience; Mudan starts by accompanying her husband as a wife, but takes over the role of rebel leader from her husband during the climax, then again displays passiveness and submission with a forced marriage at the end when her husband dies. Henochowicz (2011) states that in folklores of revolt, women and other peripheral characters get the opportunity to become courageous heroes. As a graphic adaptation of a folklore story, the comic Gada Meilin supports this argument with the female protagonist. Ling-Long, however, does not derive from folklore, nor is it a story about revolution. This could be the reason why the author refused to construct a heroine-like identity for Long.

I would also like to comment on the characters from my view as an illustrator. In terms of the visual representation of their ethnicity, I suggest that the authors could have further developed their exploration of the method of visually representing the characters' ethnic minority identity. Both the characters' ethnicities are distinguished mainly by their dress, which is not only an overused visual method for creating ethnic minority characters, but also one that reinforces typically Chinese audience's stereotypes of ethnic minority people. One may argue that considering the genre and historical context of the stories, using ethnic dress for the character design is appropriate and already enough for the readers to identify their ethnic identities. But it would be worthwhile to investigate further, especially within a graphic narrative such as the comic medium, these visual tactics which involves both image (non-verbal) and text (verbal). Although we have a strong tendency to make meanings from non-verbal information (Duncan, Taylor and Stoddard, 2016), I suggest that verbal aspects could also construct characters in comics. As stated earlier, ethnic minority culture in China is usually distinguished by cultural and linguistic factors. This approach is not fully utilised in the two comics discussed above - the only 
linguistic signifiers are the names of the characters, which are transliterations, or read like transliterations of names in an ethnic minority language.

Fashion is a conventional way to perform cultural identity. How could we visually represent other aspects of culture (such as customs, beliefs or philosophical views) and linguistic factors in the graphic narrative? I argue that this is where the development of verbal aspects should step in. A straightforward way would be by giving the characters names from their ethnic origin, which has been shown in the comics here. The more challenging approach would be interrogating their way of speech and ethnical dialects, which would require fieldwork and ethnographic research in ethnic minority areas. This could be challenging both to the artist and the reader, as the artist needs to explore different and new visual methods of depicting these intangible components of language use, while the reader needs to interpret the artist's visual methods to understand the message conveyed in its distinctive cultural context. As for the representation of femininity, common visual cues of gender were used by the artists of both works: long eyelashes for Long and floral decorations for Mudan. Comic characters are often highly simplified and symbolised, thus using clichéd visual signifiers is an effective way of displaying gender throughout the imagery, as the characters are not depicted to the extent of photo-realism that readers can recognise their genders by analysing their physical details. The following questions would be useful for the artists to ask themselves: how would women from that particular ethnic group speak differently from men? What are the words women tend to use that men would avoid? This also requires some ethnographic research, especially if the artist is trying to avoid falling back onto gender and ethnic stereotyping.

The graphical constructions of the characters have not been discussed in this paper and are worth more exploration. By graphical construction, I am referring to the artistic construction of the characters in the comic panels. Comic as sequential graphic narrative has its distinctive ways of storytelling with its vocabulary of panels, transitions, gutters and emanata and so on. Factors such as figure size, panel size, point of view and distance would influence the meanings that a certain character conveys to readers. The reader's capacity for understanding the visual grammar of comics also affects their understanding and consumption of the character's portrayal, and we need more research on the cultural symbolism of gender and ethnicity in Chinese comics and its impact, going forward.

\section{ACKNOWLEDGEMENTS}

I gratefully acknowledge the support of my supervisors, Andrew Selby and Paul Wells, for their help with my $\mathrm{PhD}$ project and their advice on my research on Chinese ethnic minority representation.

\section{REFERENCES}

Barnes, R. and Eicher, J. B. (1992). Dress and Gender. Oxford: Berg.

Bishko, L. (2007). The uses and abuses of cartoon style in animation. Animation Studies, 2, 24-35.

Brown, J. A. (2001). Black Superheroes, Milestone Comics, and Their Fans. London: University Press of Mississippi.

Central Office of Information. (1997). Ethnic Minorities. 2nd edn. London: HMSO.

Chu, Y. (2018). Visualizing minority: Images of ethnic minority groups in Chinese elementary social studies textbooks. Journal of Social Studies Research, 42(2), 135-147.

Clark, P. (1987). Ethnic minorities in Chinese films: Cinema and the exotic. East-West Film Journal, 1(2), 15-32.

Crawford, P. (2004). Using graphic novels to attract reluctant readers. Library Media Connection, 27, 26-28.

Dejide. (2008). Gada Meilin Zhi Qi - Mudan. Dangan yu Shehui, 1, 30-32.

De Vos, G. A. (1995). Ethnic pluralism: Conflict and accommodation. In Romanucci-Ross, L. and De Vos, G. A. (eds.), Ethnic Identity: Creation, conflict and accommodation (pp.15-47). Walnut Creek: AltaMira, pp. 15-47.

Dillon, M. (2016). Majorities and minorities in China: An introduction. Ethnic and Racial Studies, 39(12), 2079-2090.

Duncan, R., Taylor, M. R. and Stoddard, D. (2016). Creating Comics as Journalism, Memoir, and Nonfiction. Oxford: Routledge.

Eicher, J. B. (ed.) (1995). Dress and Ethnicity. Oxford: Berg.

Facciani, M., Warren, P. and Vendemia, J. (2015). A content-analysis of race, class, and gender in American comic books. Race, Gender \& Class, 22(3-4), 1-12.

Fan, K. (2016). Representation of ethnic minorities in socialist China. Ethnic and Racial Studies, 39(12), 2091-2107.

Gladney, D. C. (1995). Tian Zhuangzhuang, The 'Fifth Generation'and 'minorities films' in China: A review essay. Public Culture, 8(1), 161-175.

Glascock, J. and Preston-Schreck, C. (2004). Gender and racial stereotypes in daily newspaper comics: A timehonored tradition? Sex Roles, 51(7/8), 423-431. 
Harrell, S. (1995). Introduction: Civilizing projects and the reaction to them. In S. Harrell (ed.), Cultural Encounters on China's Ethnic Frontiers (pp. 3-36). Washington: University of Washington Press.

Henochowicz, A. (2011). 'For the land of all Mongols': Gada Meiren the bandit, hero, and proto-revolutionary. Journal of Wenzhou University: Social Sciences, 24(2), 44-50.

Joniak-Lüthi, A. (2015). The Han: China's diverse majority. Seattle: University of Washington Press.

Li, Y. (2000). Representations of ethnic minorities in Chinese propaganda posters, 1957-1983. MCLC Resource Center. Available at: http:/ /u.osu.edu/mclc/online-series/minzu/ (Accessed: 11 November 2018).

Liang, T. (2011). Zhongguo Zhuangzu. Yinchuan: Ningxia People's Press.

Mackerras, C. (1987). Contemporary Chinese social science study of the minority nationalities. In Yahuda, M. B. (ed.), New Directions in the Social Sciences and Humanities in China (pp. 89-113). Basingstoke: Macmillan.

Modood, T., Berthoud, R., Lakey, J., Nazroo, J., Smith, P., Virdee, S. and Beishon, S. (1997). Ethnic Minorities in Britain: Diversity and disadvantage. London: Policy Studies Institute.

Ono, K. (2007). The long flight of manga and anime: The history of comics and animation in Japan. In Cholodenko, A. (ed.) The Illusion of Life II: More essays on animation (pp. 99-118). Sydney: Power.

Pauwels, L. (2011). An intergrated conceptual framework for visual social research. In E. Margolis and L. Paulwels (eds.), The SAGE Handbook of Visual Research Methods (pp. 3-23). London: SAGE.

Poston, D. L. and Yaukey, D. (eds.). (1992). The Population of Modern China. New York: Plenum Press.

Qin, Q., Wall, G. and Liu, X. (2011). Government roles in stimulating tourism development: A case from Guangxi, China. Asia Pacific Journal of Tourism Research, 16(5), 471-487.

Romanucci-Ross, L. and De Vos, G. (eds.). (1995). Ethnic Identity: Creation, conflict, and accommodation. 3rd edn. Walnut Creek: AltaMira.

Singer, M. (2002). 'Black skins' and white masks: Comic books and the secret of race. African American Review, 36(1),107-119.

Snowball, C. (2005). Teenage reluctant readers and graphic novels. Young Adult Library Services, 3(4), 43-45.

Snowball, C. (2007). Researching graphic novels and their teenage readers. Library and Information Science, 17(1), 120.

Tao, R. (2017). Yi Manhua Huiben Wei Zai Ti Cu Jin Miao Zu Wen Hua Chuan Bo De Yan Jiu. Da Zhong Wen Yi, 16,38 .

Turton, D. and Gonzalez, J. (eds.). (1999). Cultural Identities and Ethnic Minorities in Europe. Bilbao: University of Deusto.

Wallis, C. (2011). New media practices in China: Youth patterns, processes, and politics, International Journal of Communication, 5, 406-436.

Wei, H. (2018). Nvxing Zhuyi Shiye zhong de Shaoshu Minzu Ticai Dianying. Movie Literature, 14, 23-35.

Yang, L. (2011). Ethnic tourism and cultural representation. Annals of Tourism Research, 38(2), 561-585.

Yang, L. and Wall, G. (2009). Ethnic tourism: A framework and an application. Tourism Management, 30(4), 559570.

Yang, L., Wall, G. and Smith, S. L. J. (2008). Ethnic tourism development: Chinese Government perspectives. Annals of Tourism Research, 35(3), 751-771.

Yuan, J. (2014). 'Shiqi Nian' Shaoshu Minzu Ticai Dianying zhongde Nvxing Xingxiang Tanxi. Dažbong Wenyi, 1, 189-190.

Yuan, J., Mo, H. and Cao, X. (2012). E Lun Chun Ti Cai Lianhuanhua Min Zu Biao Shi Tu Xiang Jie Xi. Zhongguo Mei Shu, 2, 118-119.

Zhang, X. (2018). Jiyu ACG Xing Shi De Guangxi Minzu Min Jian Wu Dao Yi Shu De Chuan Bo Fang Fa Yan Jiu. Xi Ju Zhi Jia, 15, 120-121.

Zhang, Y. (1997). From 'minority film' to 'minority discourse': Questions of nationhood and ethnicity in Chinese cinema. Cinema Journal, 36(3), 73-90.

Citation: Tan, X. (2020). Ethnic Minority Women in Contemporary Chinese Comics: Design, Role and Identity. Feminist Encounters: A Journal of Critical Studies in Culture and Politics, 4(1), 07. https://doi.org/10.20897/femenc/7911

Copyright (C) 2020 by Author/s and Licensed by Lectito BV, Netherlands. This is an open access article distributed under the Creative Commons Attribution License which permits unrestricted use, distribution, and reproduction in any medium, provided the original work is properly cited. 